\author{
А. Ч. Пиперски \\ НИУ «Выстая школа экономики» \\ Российский государственный гуманитарный университет \\ (Россия, Москва) \\ apiperski@gmail.com
}

\title{
КОРПУСНЫЕ НАБЛЮДЕНИЯ НАД СМЕШЕНИЕМ РОДИТЕЛЬНОГО И ПРЕДЛОЖНОГО ПАДЕЖЕЙ РУССКИХ СУЩЕСТВИТЕЛЬНЫХ
}

В статье рассматривается смешение форм родительного и предложного падежей во множественном числе русских существительных: в тринадиати предыдущих случаев, из многочисленных публикациях вместо в тринадцати предылущих случаях, из многочисленных публикаций. Такое смешение известно уже с XV в., но все же остается за пределами нормативной грамматики. Оно особенно вероятно после определений, которые не различают родительный и предложный падежи во множественном числе. На основе данных интернет-корпуса «Araneum Russicum Maius» показано, что это смешение отчасти обусловлено фонетическими и морфологическими факторами: местом ударения в формах родительного и предложного падежей и ненулевым окончанием родительного падежа (формы родительного падежа с безударным ненулевым окончанием больше похожи на предложный падеж и легче подвергаются смешению). Однако есть и другие факторы, способствующие смешению, а именно некоторые синтаксические конструкции («y + определение + предложный падеж вместо родительного», «в / о(б) одном / каждом / любом / некоторых из + определение + предложный падеж вместо родительного») и стилевая принадлежность текста (в текстах официально-делового стиля часто встречается замена предложного падежа на родительный).

Ключевые слова: русский язык, морфология, корпус, вариативность, падежный синкретизм.

Исследователи давно обращали внимание на тот факт, что в современном русском языке часто наблюдается смешение форм родительного и предложного падежей. Особенно распространено оно во множественном числе:

(1) Жозе впервые отыгрался, проигрывая два мяча в ЛЧ. В тринадцати предыдущих случаев все заканчивалось поражением [Sports.ru] (вместо В тринадиати предьдущих случаях). 
Это явление подробно исследовалось в работах М.Я. Гловинской [1996; 1998; $2008 ; 2012]$. Оно отмечается уже с XV в., и древнейшие примеры обычно объясняются южнославянским, в частности сербским, влиянием [Гловинская 2012, со ссылкой на: Keipert 1968; Казимова 2019]. Однако такое совпадение двух форм не требует внешнего объяснения и выглядит вполне естественным и с точки зрения системы русского языка: если выстроить шесть основных русских падежей в таком порядке, чтобы синкретизм наблюдался только между соседними падежами [Plank 1991; Caha 2009], получим следующую последовательность, в которой Р. и П. действительно стоят рядом:

И. - В. - Р. - П. - Д. - Т. ${ }^{1}$

На фонематическом уровне родительный падеж совпадает с предложным в следующих категориях форм:

1) существительные III склонения и разносклоняемые существительные в единственном числе, например двери, пути, знамени;

2) прилагательные и причастия (в том числе субстантивированные) и местоимения-прилагательные женского рода в единственном числе, например большой, красивой, кондитерской, моей;

3) прилагательные и причастия (в том числе субстантивированные) и местоимения-прилагательные во множественном числе, например больших, красивых, чаевых, моих;

4) большинство количественных числительных, например полутора, двух, двадиати, сорока.

Если учесть также случаи, где родительный падеж совпадает с предложным на фонетическом уровне, после действия редукции гласных, к этому списку добавляется еще несколько случаев:

1) существительные I склонения с основой на мягкий согласный, например Р. доли П П. доле;

2) существительные II склонения среднего рода с основой на мягкий согласный, например Р. чудовища $\approx$ П. чудовище.

Неудивительно, что в таких условиях говорящие на русском языке часто путают формы Р. и П. Смешение форм у существительных кажется особенно вероятным во множественном числе в случае, когда они стоят после определений, у которых Р. и П. и так совпадают: на этих принципов; о других переговоров; от своих лидерах; повторение каких-то механических жестах. По наблюдению М. В. Русаковой, «неадекватное предложно-падежное оформление словоформы существительного является одним из самых частотных сбоев, фиксируемых в русской речи» [Русакова 2013: 126]. Одним из типов таких сбоев является «неадекватное подстраивание под словоформу с адъективными окончаниями. Причина сбоя связана

1 Здесь и далее русские падежи обозначаются общепринятыми сокращениями по первой букве названия: И(менительный), Р(одительный), Д(ательный), В(инительный), Т(ворительный), П(редложный). 
с синкретизмом в парадигме адъективного склонения» [Там же: 127]. Еще один важный фактор - фонетическая близость безударных окончаний -ов и -ax, которую мы наблюдаем во всех приведенных выше примерах [Гловинская 2012: 180].

Как отмечает М.Я. Гловинская, «строго научный результат дало бы статистическое обследование: постоянное наблюдение над речью одной и той же группы испытуемых в течение одного и того же длительного времени и подсчет соотношения правильных форм и ошибок». Однако она сразу же добавляет, что «статистическое обследование в таких случаях невозможно и технически, и содержательно» [Гловинская 2012: 180].

Как бы то ни было, другой тип статистического исследования - корпусный анализ примеров со смешением падежей - кажется в данном случае вполне уместным. Во-первых, можно проверить гипотезу о том, что некоторые классы существительных более склонны к смешению Р. ↔ П., чем другие. Во-вторых, корпусный анализ позволит выделить контексты, в которых такое смешение окажется более вероятным.

Правда, классические корпуса русского языка, такие как основной подкорпус «Национального корпуса русского языка» или «СинТагРус», плохо подходят для решения этой задачи, поскольку обычно содержат хорошо вычитанные тексты а для того, чтобы изучать явление, которое говорящими на русском языке все же воспринимается как ошибка, нужен корпус более спонтанных текстов. Поэтому для того, чтобы получить выборку примеров и статистику, был использован корпус «Araneum Russicum Maius» [Araneum Russicum Maius; Benko 2014] общим объемом 1 млрд словоформ, который содержит тексты, автоматически скачанные из интернета.

При использовании корпуса возникает проблема: невозможно легко установить, является ли произвольно выбранная форма Р. или П. законной или представляет собой результат смешения. Возможный путь состоит в том, чтобы вручную просматривать случайную выборку существительных, определенных как Р. или П., отбирая ошибочные формы, однако это потребовало бы ручной обработки слишком большого объема материала, поскольку мы имеем дело с крайне редким явлением. Поэтому был выбран другой путь: исследуются факторы, которые влияют на смешение Р. и П. во множественном числе существительных только в тех контекстах, где ожидаемый падеж легко предсказывается окружением, а именно после характерных для Р. и П. предлогов в сочетании с определением. Разумеется, это очень сильно сужает объем исследуемого материала, однако такое сужение можно считать оправданным, во всяком случае, для первого корпусного приближения к проблеме.

Примеры замены Р. $\rightarrow$ П. извлекались из корпуса с помощью следующего запроса:

[lc="без|для|до|из|из-за|из-под|от|y"] [lc=".*x"] [lc=".*[ая] x" \& tag="N.*"]

(1-е слово - предлог без, для, до, из, из-за, из-под, от, y;

2-е слово - любое слово, оканчивающееся на $-x$;

3-е слово - любое не менее чем двухбуквенное слово, оканчивающееся на - $а x$ или -яx, автоматически размеченное как существительное N). 
Примеры замены П. $\rightarrow$ Р. извлекались из корпуса с помощью следующего запроса: [lc="при|о|об"] [lc=".*[^ая]x" \& lc!="них"] [tag="N..pg.*" \& lc!=".*[ыи]x"] (1-е слово - предлог при, о или об;

2-е слово - любое не менее чем двухбуквенное слово, оканчивающееся на $-x$, перед которым следует не $a$ и не $я$ (чтобы исключить в этой позиции существительные), но не слово них;

3-е слово - любое слово, автоматические размеченное как существительное $(\mathrm{N})$ в родительном падеже $(\mathrm{g})$ множественного числа (p), не оканчивающееся на -blx или -ux, чтобы исключить словосочетания с субстантивированными прилагательными типа о хороших кондитерских, где нельзя говорить о смешении падежей).

По первому запросу (Р. $\rightarrow$ П.) было найдено 1887 примеров; ручная обработка случайной выборки, состоящей из 400 примеров, позволила обнаружить 178 контекстов, действительно иллюстрирующих интересующее нас явление. Таким образом, точность запроса составляет $44,5 \%$, что позволяет ожидать, что при рассмотрении всего материала было бы обнаружено около $1887 \times 0,445=840$ примеров смешения Р. $\rightarrow$ П.

По второму запросу (П. $\rightarrow$ Р.) было найдено 1574 примера; ручная обработка случайной выборки, состоящей из 400 примеров, позволила обнаружить ровно столько же - 178 примеров, действительно иллюстрирующих замену П. $\rightarrow$ Р. Таким образом, и в этом случае точность запроса составляет 44,5\%, а значит, при рассмотрении всего материала было бы обнаружено около 1574 × 0,445 = 700 примеров смешения Р. $\rightarrow$ П.

Для проверки были сформулированы три гипотезы о факторах, связанных с видом ожидаемого (правильного) и наблюдаемого (неправильного) окончаний, которые способствуют смешению Р. $\leftrightarrow$ П.:

(i) ожидаемое окончание не должно быть слишком заметным, т.е. ударным: иными словами, ударение в ожидаемой форме должно быть на основе;

(ii) ожидаемое и наблюдаемое окончания должны быть похожи друг на друга фонетически - различаться только одним звуком, что возможно лишь для безударных окончаний Р. [-ъф] и П. [-ъх] или Р. [-ьй] и П. [-ьх];

(iii) наблюдаемое окончание не должно быть слишком заметным, т. е. ударным; иными словами, ударение в наблюдаемой форме должно быть на основе.

В зависимости от схемы ударения и окончания в Р. мн. ч. (-ов(-ев)/-ей/ нулевое) можно выделить шесть типов существительных, которые, как мы ожидаем, будут в разной мере склонны смешивать родительный и предложный падежи. Эти типы представлены в табл. 1.

Естественно предполагать, что наиболее часто смешение будет наблюдаться в словах типа заво́дов, ра́достей, а в остальных типах — реже. Для того чтобы проверить это, сформулируем ту же гипотезу иначе: мы ожидаем, что в выборке примеров со смешением Р. ↔ П. встретится заметно больше слов типа заво́дов, pádостей, чем в контрольной выборке примеров без смешения. 
Типы существительных и факторы, способствуюшие смешению Р. $\leftrightarrow$ П. $^{2}$

\begin{tabular}{|l|l|c|c|c|}
\hline Пример (Р.) & Пример (П.) & Ударение в Р. на основе & Похожие окончания & Ударение в П. на основе \\
\hline заво́дов & заво́дах & + & + & + \\
\hline ра́достей & ра́достях & + & + & + \\
\hline стра́н & стра́нах & + & - & + \\
\hline ме́ст & места́x & + & - & - \\
\hline столо́в & стола́x & - & - & - \\
\hline доле́й & доля́x & - & - & - \\
\hline
\end{tabular}

Для того чтобы получить контрольную выборку без смешения, был использован корпус [СинТагРус], в котором проведено ручное снятие морфологической омонимии. Из этого корпуса было извлечено по 178 случайных форм Р. мн. ч. и П. мн. ч. существительных. Вот для примера по 15 форм из этих двух выборок:

Р.: пунктов, политиков, альпинистов, переговоров, узников, аллюзий, блоков, стран, союзников, рельсов, форм, граждан, ботинок, работников, сил;

П.: вариантах, женщинах, похоронах, направлениях, районах, силах, школах, случаях, окрестностях, рублях, странах, проявлениях, цилиндрах, лесах, корпусах.

Следующий шаг исследования - сравнить частотность форм с теми или иными характеристиками в выборке примеров со смешением и в выборках законных форм Р. и П. из [СинТагРус]. Так, например, из 178 примеров со смешением Р. $\rightarrow$ П только в четырех случаях мы обнаруживаем в получившейся форме ударение на окончании:

(2) . ... мы рады приветствовать Вас у наших берегах...

(3) Антиквариатом принято считать вещи, сделанные до 1930-х годах...

(4) ... для преследуемого украиниа из Восточных областях логично уехать в Западные области и наоборот.

(5) У курортных местах своя жизнь, которая как магнит притягивает мир криминала.

Много это или мало - 4 примера из 178 с ударением на окончании в П. и, наоборот, 174 примера из 178 с ударением на основе? Чтобы понять это, надо выяснить, у какой доли слов, законно употребленных в форме Р., при постановке в П. получилось бы ударение на основе и на окончании. Для 178 примеров, извлеченных из [СинТагРус], оказывается, что ударение на основе имело бы 161 слово, а на окончании - 17 . Таким образом, в выборке со смешением оказывается 174 / $178=97,8 \%$ слов с ударной основой, а в выборке правильно употребленных форм Р. - $161 / 178=90,4 \%$ таких слов. Применяя к этим данным двухвыборочный тест пропорций (prop.test в R), можно убедиться, что результат достаточно статистически значим $(p=0,007)$. Таким образом,

${ }^{2}$ Сюда не включены единичные случаи, в которых Р. и П. различаются ударением, но это различие не обусловлено только нулевым окончанием в Р., как в типе ме́ст-места́x. Так устроены, по крайней мере, слова люде́й лю́дяx, дете́й де́тяx, а также (в идиолекте автора статьи, который здесь расходится со словарями) ме́сящев месяй́x. 
мы проверили гипотезу, обозначенную выше как (iii): слова, у которых в результате смешения Р. $\rightarrow$ П. получается ударное окончание в форме П., менее склонны подвергаться этому смешению, чем слова, у которых получается ударная основа.

Практически такой же результат дает проверка гипотезы (i): слова, которые имеют ударное окончание в форме Р., менее склонны подвергаться смешению Р. $\rightarrow$ П., чем слова с ударной основой. В выборке со смешением таких примеров всего три, а именно (2)-(4); пример 5 выпадает, поскольку в слове ме́ст ударение в Р. благодаря нулевому окончанию стояло бы на основе. Итак, доля ударений на основе составляет здесь 175 / $178=98,3$ \%. Среди законных Р. доля ударений на основе $163 / 178=91,6 \%$. И в этом случае двухвыборочный тест пропорций показывает, что различие достаточно значимо $(p=0,008)$.

Аналогичным образом можно протестировать и гипотезу (ii). Поскольку ударение мы уже проверили, причем дважды, ограничимся только проверкой фонемного состава окончаний. Гипотеза (ii) обращает внимание на схожесть двухфонемных окончаний Р. и П. (-ов/-ей и - $a x /-я x)$ и несхожесть нулевого окончания Р. с двухфонемным окончанием П. Иными словами, мы предполагаем, что двухфонемное окончание Р. благоприятствует смешению Р. $\rightarrow$ П., а нулевое препятствует смешению; таким образом, в выборке со смешением доля ненулевых окончаний будет больше, чем среди законных форм Р. Эта закономерность действительно соблюдается: ненулевых окончаний Р. у слов со смешением - 132 / $178=74,2 \%$, а без смешения - $99 / 178=55,6 \%(p=0,0004)$.

Можно проверить и комбинации факторов, опираясь на выделенные выше типы слов. Под табл. 1 была высказана гипотеза, что слова типа заво́дов, pádостей будут значимо чаще встречаться в выборке со смешением, чем среди законных форм P., — и действительно, в первой выборке их $129 / 178=72,5 \%$, а во второй $83 / 178=46,7 \%(p=0,000001)$.

Итак, статистические данные позволяют считать, что ударность основы в формах Р. и П. и ненулевое окончание в форме Р. действительно способствуют смешению Р. $\rightarrow$ П. Обобщим это в виде табл. 2.

Следующий исследовательский вопрос состоит в том, есть ли какие-то конструкции, которые особенно способствуют смешению Р. $\rightarrow$ П. Материал слишком мал, чтобы делать уверенные количественные обобщения, однако просмотр примеров позволяет выделить два характерных типа употреблений.

Первый из них - это конструкция обладания с предлогом $y$, которая легко может быть переинтерпретирована как конструкция места. Эти случаи можно описать так: автор использовал предлог y, но продолжает предложение так, как будто использовал предлог в. Смешению способствует и фонетическая близость у и в. Именно так устроен пример 5, а также примеры 6-7:

(6) ... на баке у некоторых моделях авто установлен топливный насос... ( $\approx$ в некоторых моделях);

У вентиляционных решетках для каминов предусмотрены отверстия ( $\approx$ В вентиляционных решетках). 
Сравнение выборки со смешением P. $\rightarrow$ П. с законными формами $P$

\begin{tabular}{|c|c|}
\hline Смешение Р. $\rightarrow$ П. & Законные Р. [СинТагРус] \\
\hline \multicolumn{2}{|c|}{ Ударение на основе в Р. } \\
\hline $175 / 178=98,3 \%$ & $163 / 178=91,6 \%$ \\
\hline \multicolumn{2}{|c|}{$p=0,008$} \\
\hline \multicolumn{2}{|c|}{ Ненулевое окончание в Р. } \\
\hline $132 / 178=74,2 \%$ & $99 / 178=55,6 \%$ \\
\hline \multicolumn{2}{|c|}{$p=0,0004$} \\
\hline \multicolumn{2}{|c|}{ Ударение на основе в П. } \\
\hline $174 / 178=97,8 \%$ & $161 / 178=90,4 \%$ \\
\hline \multicolumn{2}{|c|}{$p=0,007$} \\
\hline \multicolumn{2}{|c|}{ Тип заво́дов, ра́достей } \\
\hline $129 / 178=72,5 \%$ & $83 / 178=46,7 \%$ \\
\hline \multicolumn{2}{|c|}{$p=0,000001$} \\
\hline
\end{tabular}

Во второй конструкции, способствующей смешению, П. копируется с более высокого уровня синтаксической структуры. Речь идет о случаях типа в / o(б) одном / каждом / любом / некоторых из Adj X:

(8) . ... ни в одной из многочисленных публикациях в СМИ об убийстве Аксельрода толком не сказано, чем занимался погибший... ( $\approx$ ни в одной публикаиии);

(9) На одном из юридических форумах обсуждалась данная тема... ( $\approx$ на одном форуме);

(10) . . в в некоторых из бедных поселках были поджоги палаток для голосования ( $\approx$ в некоторых поселках).

Теперь рассмотрим обратное явление - смешение П. $\rightarrow$ Р., например:

(11) Есть смысл говорить о местных чиновников, которые продвигают проект застройки...

Можно было бы ожидать, что оно будет стимулироваться теми же факторами, что и смешение Р. $\rightarrow$ П., а именно ударением на основе в Р. и П. и ненулевым окончанием Р., однако это не вполне подтверждается (см. табл. 3).

Как видно из табл. 3, ненулевое окончание не оказывается значимым фактором и тип заво́дов, ра́достей не представлен среди примеров со смешением слишком многочисленно. Более того, тип стра́н (ударение на основе в Р. и П. и нулевое окончание Р.) даже ближе подходит к принятому порогу статистической значимости 0,05 .

Объяснение этому факту обнаруживается при анализе примеров. Если примеры Р. $\rightarrow$ П. в основном происходят из разговорных текстов, то стилистический облик текстов с П. $\rightarrow$ Р. совсем иной:

(12) Причиной (sic! - А. П.) неразвитости данной связи лежит как в объективных условиях: относительная недоступность лизинговых услуг для клиентов «с улицы» и непривлекательность лизинговых услуг для них при существующих условий финансирования, так и в субъективных... 
Сравнение выборки со смешением П. $\rightarrow$ Р. с законными формами П

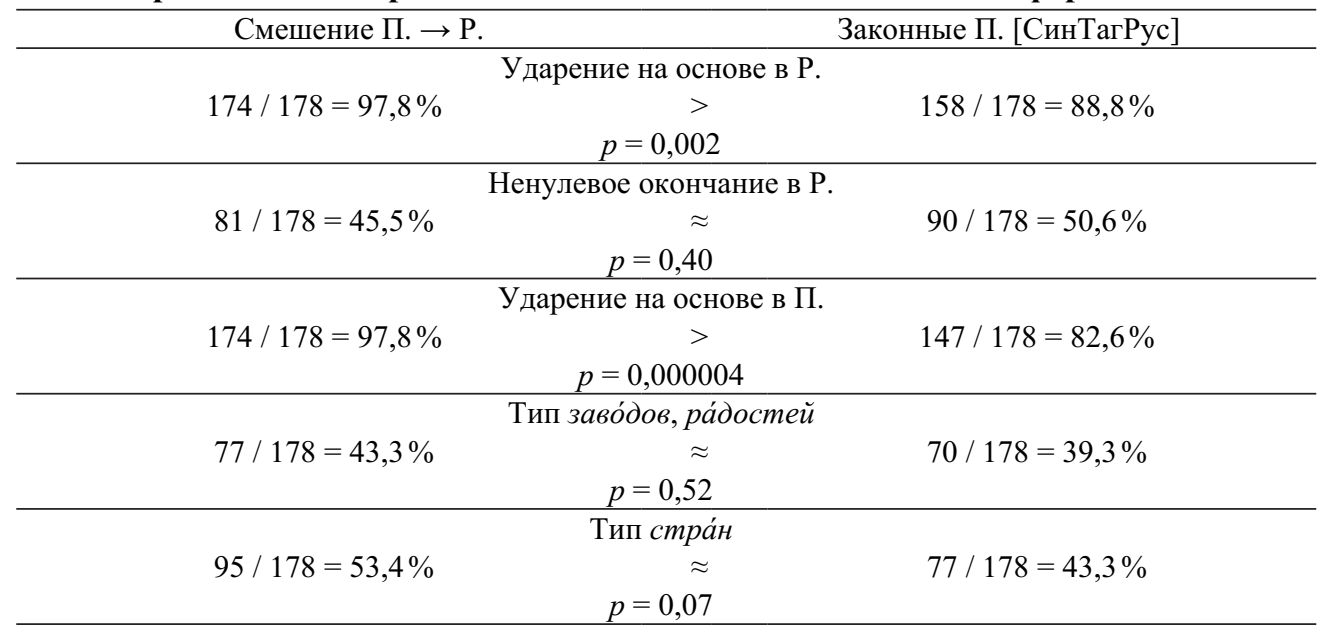

(13) В первую очередь изучается их высокая способность снижать уровень холестерина и их восстановительные свойства при определенных видов рака.

(14) В связи с тем, что вышеуказанные нормативные правовые акты направлены на предотвращения совершения правонарушений в сфере иченообразования, доведение до сведения субъектов предпринимательства более полной информаџии об обязательных требований действующего законодательства в определенной сфере деятельности, предлагаемый к разработке проект Методических рекомендаций фактически продублирует нормы действующего федерального и регионального законодательства.

Легко видеть, что смешение П. $\rightarrow$ Р. характерно для текстов официально-делового стиля (или, говоря резче, но яснее: для канцелярита, с которым автор не справился). В таких текстах частота Р. повышена по сравнению с общеязыковой, и неудивительно, что возникает неосознанное желание еще увеличить число форм Р. А частотность существительных на -ние среди примеров со смешением (ср. в примере 14: требований вместо требованиях), которые имеют нулевое окончание Р., способствует тому, что для смешения П. $\rightarrow$ Р. фактор ненулевого окончания Р. оказывается незначимым.

Поскольку выше проанализирована лишь небольшая выборка удобных для автоматического извлечения контекстов, полученные результаты нельзя считать полным описанием смешения Р. $\leftrightarrow$ П. во множественном числе русских существительных. Однако на основании корпусного анализа можно все же достаточно уверенно сказать, что это смешение отчасти обусловлено фонетическими и морфологическими факторами (местом ударения в формах Р. и П. и ненулевым окончанием Р.), но есть и другие факторы, способствующие ему, а именно некоторые синтаксические конструкции и стилевая принадлежность текста. 


\section{Литература}

Гловинская М.Я. Активные процессы в грамматике (на материале инноваций и массовых языковых ошибок) // Русский язык конца XX столетия (1985-1995) / отв. ред. Е. А. Земская. М. : Языки русской культуры, 1996. С. 237-304.

Гловинская М. Я. Просто оговорки или тенденция к аналитизму? // Язык: изменчивость и постоянство. К 70-летию Л. Л. Касаткина / отв. ред. М. Л. Каленчук. М. : ИРЯ РАН, 1998. С. 304-316.

Гловинская М.Я. Активные процессы в грамматике // Современный русский язык. Активные процессы на рубеже XX-XXI веков / отв. ред. Л.П. Крысин. М. : Языки славянских культур, 2008. С. 187-270.

Гловинская М.Я. О чем свидетельствует реакция носителей языка на грамматические инновации // Вопросы культуры речи. Вып. 11 / отв. ред. А. Д. Шмелев. М. : Языки славянской культуры, 2012. С. 178-185.

Казимова Г.А. О возможном сербском компоненте в связи с меной генитива и локатива мн. ч. существительных в славянском тексте гомилий Василия Великого на псалмы и некоторых других святоотеческих текстах (ГИМ, Син-238, лл. 456786), считающихся переводами Максима Грека // Црквене студије. 2019. № 16/2. C. 659-672.

Русакова М.В. Элементы антропоцентрической грамматики русского языка. М. : Языки славянской культуры, 2013. 568 с.

СинТагРус — GitHub - UniversalDependencies/UD_Russian-SynTagRus: Russian data from the SynTagRus corpus [Электронный pecypc]. URL: https://github.com/ UniversalDependencies/UD Russian-SynTagRus

Araneum Russicum Maius - Comenius NoSkE: Araneum Russicum Maius [Электронный ресурc]. URL: http://unesco.uniba.sk

Benko $V$. Yet another family of (comparable) Web corpora // Text, Speech and Dialogue. $17^{\text {th }}$ International Conference (Brno, Czech Republic, September 8-12, 2014) / ed. by P. Sojka, A. Horák, I. Kopeček, K. Pala. Cham : Springer International Publishing Switzerland, 2014. P. 247-256.

Caha P. The nanosyntax of case $: \mathrm{PhD}$ dissertation / University of Tromsø. Tromsø, 2009. $321 \mathrm{p}$.

Keipert H. Beiträge zur Textgeschichte und Nominalmorphologie des «Vremennik Ivana Timofeeva» : Inauguraldissertation / Rheinische Friedrich-Wilhelms-Universität. Bonn, 1968. $287 \mathrm{p}$.

Plank F. Rasmus Rask's dilemma // Paradigms: The economy of inflection / ed. by F. Plank. Berlin : Mouton de Gruyter, 1991. P. 161-196. 


\author{
A.Ch. Piperski \\ Higher School of Economics \\ Russian State University for the Humanities \\ (Russia, Moscow) \\ apiperski@gmail.com
}

\section{CORPUS-BASED OBSERVATIONS ON THE CONFUSION OF GENITIVE AND LOCATIVE IN RUSSIAN NOUNS}

The paper describes the confusion of the genitive and of the locative in the plural of Russian nouns: $v$ trinadcati predyduščix slučaev, iz mnogočislennyx publikacijax instead of $v$ trinadcati predyduščix slučajax 'in thirteen previous cases,' iz mnogočislennyx publikacijax 'from numerous publications.' This confusion has been known since the $15^{\text {th }}$ century, but it is still not accepted as grammatically correct in Standard Russian. It is especially likely in nouns after attributes (adjectives, pronouns, and numerals) that do not distinguish the genitive and the locative in the plural. The analysis of the data from Araneum Russicum Maius corpus shows that this confusion is partly due to phonological and morphological factors, namely the location of stress in genitive and locative plural and the presence of a non-zero ending in the genitive (if a noun has a non-zero unstressed ending in the genitive plural, the use of the incorrect form is more probable). However, there are some other factors favoring confusion. It is more likely in some syntactic constructions $(u+$ attribute + locative instead of genitive 'in X,' $v / o(b)$ odnom / každom / ljubom / nekotoryx iz + attribute + locative instead of genitive 'in / about one / each / any / some of X') and in formal style, where the genitive is substituted for the locative.

Key words: Russian language, morphology, corpus linguistics, linguistic variation, case syncretism.

\section{References}

Araneum Russicum Maius - Comenius NoSkE: Araneum Russicum Maius. Available at: http://unesco.uniba.sk (accessed 31.01.2020).

Benko V. Yet another family of (comparable) Web corpora. Text, Speech and Dialogue. 17 th International Conference (Brno, Czech Republic, September 8-12, 2014). P. Sojka, A. Horák, I. Kopeček, K. Pala (Eds.). Cham, Springer International Publishing Switzerland, 2014, pp. 247-256.

Caha P. The nanosyntax of case. Dr. phil. sci. diss. Tromsø, 2009. 321 p.

Glovinskaya M.Ya. [Active processes in grammar (based on innovations and frequent linguistic mistakes)]. Russkii yazyk kontsa XX stoletiya (1985-1995) [The Russian language of the end of the $20^{\text {th }}$ century (1985-1995)]. E. A. Zemskaya (Ed.). Moscow, Yazyki russkoi kul'tury Publ., 1996, pp. 237-304. (In Russ.)

Glovinskaya M.Ya. [Active processes in grammar]. Sovremennyi russkii yazyk. Aktivnye protsessy na rubezhe $X X-X X I$ vekov [The Modern Russian Language: Active 
processes at the turn of the $21^{\text {st }}$ century]. L.P. Krysin (Ed.). Moscow, Yazyki slavyanskikh kul'tur Publ., 2008, pp. 187-270. (In Russ.)

Glovinskaya M.Ya. [Mere slips of the tongue or a shift to analytism?]. Yazyk: izmenchivost' i postoyanstvo. K 70-letiyu L. L. Kasatkina [Language: variability and stability. On the occasion of Leonid Kasatkin's $70^{\text {th }}$ birthday]. M. L. Kalenchuk (Ed.). Moscow, Vinogradov Russ. Language Inst. Publ., 1998, pp. 304-316. (In Russ.)

Glovinskaya M.Ya. [What can we infer from the reaction of speakers to grammatical changes?]. Voprosy kul'tury rechi. Vyp. 11 [Topics in correct linguistic usage. Iss. 11]. A.D. Shmelev (Ed.). Moscow, Yazyki slavyanskoi kul'tury Publ., 2012, pp. 178-185. (In Russ.)

Kazimova G. A. [On eventual Serbian influence exhibited in the confusion of the genitive and the locative plural in the Slavic text of Basil the Great's homilies and some other patristic texts (State Historical Museum, Syn-238, ff. 456-786) assumed to be translated by Maximus the Greek]. Tsrkvene studije, 2019, no. 16/2, pp. 659-672. (In Russ.)

Keipert H. Beiträge zur Textgeschichte und Nominalmorphologie des "Vremennik Ivana Timofeeva". Dr. phil. sci. diss. Bonn, 1968. 287 p.

Plank F. Rasmus Rask's dilemma. Paradigms: The economy of inflection. F. Plank (Ed.). Berlin, Mouton de Gruyter, 1991, pp. 161-196.

Rusakova M.V. Elementy antropotsentricheskoi grammatiki russkogo yazyka [The Elements of anthropocentric grammar of the Russian language]. Moscow, Yazyki slavyanskoi kul'tury Publ., 2013. 568 p.

SynTagRus - GitHub - UniversalDependencies/UD_Russian-SynTagRus: Russian data from the SynTagRus corpus. Available at: https://github.com/UniversalDependencies/UD_Russian-SynTagRus (accessed 31.01.2020). 